\title{
ACESSIBILIDADE EM PROJETOS ARQUITETÔNICOS: ESTRATÉGICAS TRANSVERSAIS E PEDAGÓGICAS PARA A PROMOÇÃO DE UM PROFISSIONAL-CIDADÃO
}

\author{
ROMCY, Cristina Maria Aleme (1); \\ CARDOSO, Rafaela Ponte Lisboa (2) \\ (1) Universidade de Fortaleza, Doutora \\ e-mail:cristinaromcy@unifor.br \\ (2) Universidade de Fortaleza, Doutora \\ e-mail:rafaelaplc@unifor.br
}

\begin{abstract}
RESUMO
Dentre as atribuições do Arquiteto e Urbanista destaca-se atividades voltadas ao planejamento, desenvolvimento de projeto arquitetônico e a disposição dos equipamentos de estruturam a cidade. Para tanto, suas ações devem estar sempre pautadas em uma perspectiva social que inclua a diversidade humana. Assim, o seu processo de formação, desde a graduação a sua atuação profissional, demanda uma formatação de ordem tecnológica, econômica, integral e humanista. Diante deste contexto, este artigo visa apresentar um conjunto de estratégias pedagógicas e transversais, que possibilitem aos discentes a compreensão de sua função social enquanto um profissional-cidadão, cuja acessibilidade seja pauta do seu fazer técnico.
\end{abstract}

Palavras chave: acessibilidade; arquitetura e urbanismo; inclusão social e estratégias pedagógicas.

\begin{abstract}
Among the attributions of the Architect and Urbanist highlights activities focused on planning, development of architectural design and layout of the equipment of the city. Therefore, their actions must always be based on a social perspective that includes human diversity. Thus, its training process, from the undergraduate to its professional performance, demands a format of technological, economic, integral and humanistic order. In this context, this article aims to present a set of pedagogical and transversal strategies that allow students to understand their social function as a professional citizen, whose accessibility is the guideline of their technical work.
\end{abstract}

Keywords: accessibility; architecture and urbanism; social inclusion and pedagogical strategies. 


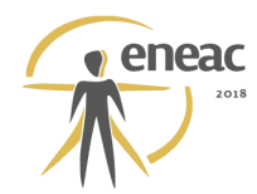

\section{INTRODUÇÃO}

Os cursos de graduação em Arquitetura e Urbanismo, de acordo com o parecer do Conselho Nacional de Educação (BRASIL, 2009), devem desenvolver nos discentes a capacidade de perceberem e expressarem as demandas das pessoas e delas em enquanto um grupo. Além disso, devem fomentar nos alunos a percepção destas necessidades frente "à concepção, à organização e à construção do espaço interior e exterior, abrangendo o urbanismo, a edificação, o paisagismo, [...] a conservação e a valorização do patrimônio construído, a proteção do equilíbrio do ambiente natural e a utilização racional dos recursos disponíveis".

A formação do Arquiteto e Urbanista precisam propiciar um processo de ensino e aprendizagem que favoreça aos discentes desenvolverem "condutas e atitudes com responsabilidade técnica e social" (BRASIL, 2009). Deste modo, o Arquiteto e Urbanista deve ter uma percepção acerca da dimensão social de suas ações enquanto profissional, pois demanda um viés humanista com foco no desenvolvimento da sociedade.

Diante deste contexto, surge o questionamento: Como fomentar no aluno a preocupação com a diversidade humana presente na sociedade no seu fazer profissional enquanto arquiteto? Assim, este artigo visa apresentar um conjunto de estratégias pedagógicas e transversais, que possibilitem aos discentes a compreensão de sua função social enquanto um profissional-cidadão, cuja acessibilidade seja pauta do seu fazer técnico.

$\mathrm{O}$ referido artigo se estrutura em outros quatro itens. No item 2, apresenta-se reflexões sobre inclusão social, acessibilidade, transversalidade à caminho do ensino em arquitetura, mas especificamente percurso teórico estruturado a partir da fundamentação teórica de alguns estudos acadêmicos que nortearam o desenvolvimento das estratégias pedagógicas e transversais. No item 3, expõe-se o relato da experiência vivenciada a partir das premissas incorporadas e implementadas por meio das estratégias. Em seguida, relata-se as conclusões e resultados obtidos, e por fim, a conclusão.

\section{REFLEXÕES SOBRE INCLUSÃO SOCIAL, ACESSIBILIDADE, TRANSVERSALIDADE À CAMINHO DA FORMAÇÃO DO ARQUITETO EURBANISTA}

O desenvolvimento das estratégias pedagógicas, visando uma formação para além do conhecimento técnico, demanda um estudo acerca da perspectiva da transversalidade. Uma abordagem complexa, que não se limita ao trabalho de temas, assuntos, conteúdos no contexto simplesmente das disciplinas.

A transversalidade não visualiza os saberes de forma dissociadas, mas sim integradas e interligadas. Assim, a formação profissional passa a ser vista pelo viés bem mais amplo. Todavia, essa prática somente será viável quando não houver mais a fragmentação do conhecimento (MORUZZI; MORUZZI, 2010) (SANTOS, 2005). Para dar tal enfoque, se estabelece a temática Inclusão Social com o destaque na acessibilidade. Adota-se esta premissa, pois percebe-se a acessibilidade como sendo a possibilidade de acesso destinada a todos. Neste sentido, o termo apresenta uma abrangência de inclusão de pessoas que "vivem determinadas situações de dificuldade às quais todos os indivíduos são passíveis de se submeterem em algum momento de suas vidas" (DUARTE; COHEN, 2003, p.7). 


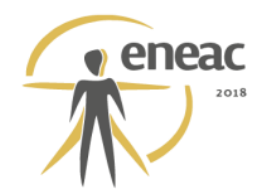

O reconhecimento de que os conceitos de acessibilidade e de inclusão social estão intrinsecamente vinculados implica em promover a efetiva participação das pessoas com deficiência na sociedade em igualdade de oportunidades com as demais pessoas.

Isso significa que todo e qualquer processo de inclusão social se apresenta em várias dimensões: a física, a social, a econômica e cultural, a saúde, a educação e a informação e comunicação. Ou seja, que possibilite é "o pleno gozo de todos os direitos humanos e liberdades fundamentais" definido na Convenção dos Direitos Humanos às Pessoas com Deficiência de 2009 (BRASIL, 2009).

A deficiência é, portanto, um conceito em evolução reconhecido pela mesma convenção (BRASIL, 2009), e que essa "deficiência resulta da interação entre pessoas com deficiência e as barreiras devidas às atitudes e ao ambiente que impedem a plena e efetiva participação dessas pessoas na sociedade em igualdade de oportunidades com as demais pessoas" requer, assim, a implementação do conceito de acessibilidade no seu sentido mais amplo.

Essa condição passa pelo reconhecimento de que o fator limitador é o meio em que a pessoa está inserida e não a deficiência em si, cujo ambiente físico e social necessita se estruturar para tornarem-se acessíveis. Trata aqui, de se construir a cidade que vai além de sua função social garantida pelo Estatuto da Cidade, mas de uma cidade sustentável que fomente a infraestrutura e mobilidade acessível e inclusiva a todos os grupos sociais.

O conceito de inclusão veio garantir o direito de ir e vir de qualquer cidadão, que prevê que os ambientes devam ser acessíveis a todos, seja pessoa com deficiência ou não. A partir desse conceito, 0 desenvolvimento das estratégias pedagógicas, que atrelam a transversalidade da acessibilidade, se processa no contexto da disciplina de Projeto Arquitetônico $V$ cujo tema escolhido é um dos equipamentos de estabelecimento assistencial de saúde, o hospitalar.

A disciplina de Projeto Arquitetônico $V$ tem dentre os seus objetivos, destaca-se o de capacitar o aluno para projetar um equipamento por meio da compreensão do ambiente hospitalar pela aplicação de critérios de espacialização das funções na edificação, determinadas pela interrelação entre as diversas atividades desenvolvidas nessa edificação. Como, por exemplo, integrar setores atendendo critérios de circulação e fluxos nas diversas unidades que compõem o hospital, para isso irá planejar a circulação de pessoas, mercadorias e veículos, atendendo as condições de acesso e parâmetros de acessibilidade; promovendo o bem estar e segurança dos usuários, por meio da adequação ambiental e apresentar proposta de projeto arquitetônico, contextualizando o desenvolvimento e os resultados alcançados, por meio de desenho técnico, memorial descritivo e recursos audiovisuais.

No item a seguir, descreve-se as estratégias adotadas para trabalhar a acessibilidade de modo transversal por meio do relato da experiência vivenciada na disciplina de Projeto Arquitetônico.

\section{RELATO DE EXPERIÊNCIA}

A disciplina Projeto Arquitetônico V estruturou-se para a realização dessa experiência, tendo como premissas: i) desenvolver no aluno a capacidade de empregar o conceito de acessibilidade e suas legislações no estudo, no planejamento e no desenvolvimento de um projeto arquitetônico de um hospital; ii) proporcionar experiências visando assimilarem a perspectiva da inclusão social e a mudança de postura frente ao seu papel enquanto 


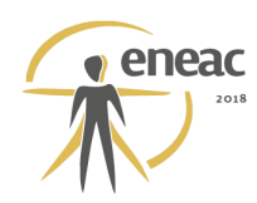

arquiteto e urbanista.

Iniciou-se às atividades da disciplina a partir da realização de uma pesquisa bibliográfica e documental, proposta aos alunos, sobre a relação do conceito de acessibilidade e a promoção da inclusão social para subsidiar as ações voltadas para as pessoas com deficiência. Em seguida, desenvolveu-se um estudo da relação entre todo conhecimento adquirido com as pesquisas e a disciplina de projeto arquitetônico hospitalar.

Em seguida, foi proposto o levantamento da legislação referente a temática e sua aplicabilidade. Concomitantemente, realizou-se uma visita de campo com o intuito de analisar um estabelecimento de saúde. Com a visita, o aluno verificou se a unidade hospitalar contemplava a acessibilidade e para quais deficiências frente às demandas exigidas. Ao final dessa experiência propõe-se a elaboração de um projeto e construção de uma sala modelo no campus da universidade à partir de vários ângulos de visão.

Antes de dar início a elaboração do projeto, foram propostas algumas atividades que começaram com a estruturação de uma situação-problema fundamentada através da leitura de documentos e da análise de objetos arquitetônicos elaborados. Assim, seguiu-se com a definição de um programa de necessidades para a edificação a ser desenvolvida. Neste modo, os alunos foram estimulados a debater os conceitos de humanização e de acessibilidade na elaboração do programa de necessidades como forma de atender aos critérios do Ministério da Saúde e de proporcionar o bem-estar frente ao uso do referido equipamento.

Vários questionamentos foram levantados junto aos alunos como: no universo da saúde qual é o papel da arquitetura? A Arquitetura Hospitalar por si só, já contempla a acessibilidade? Como a acessibilidade pode promover a inclusão social em um equipamento de estabelecimento de saúde? De que maneira um projeto de arquitetura hospitalar pode atender maior diversidade humana?

Assim, a partir dessas questões dividiu-se a turma em vários grupos para analisar a situação-problema proposta, por meio da leitura de documentos e da análise de objetos arquitetônicos elaborados de edificações similares ao tema escolhido e para apresentá-la em seguida. A atividade proporcionou uma percepção acerca da complexidade da organização e da espacialização de um hospital inclusivo.

Com exercício supracitado, o saber dos alunos foi valorizado. Com a ação, os discentes puderam relatar suas experiências e compartilhar o conhecimento que foi construído entre eles, contribuindo assim, com a formação de um aluno reflexivo, tornando-os protagonistas de seu processo de aprendizagem (SILVEIRA et al., 2009).

Em paralelo aos momentos de discussão em grupo, realizaram-se aulas expositivas dialogadas que trataram da evolução histórica desse equipamento, tanto física como de finalidade. Destacou-se que a tipologia varia de acordo com a classificação existente para cada tipo de atendimento existente na rede de saúde do Brasil, sua terminologia e sua inserção na cidade de modo a dialogar com o entorno.

Posteriormente, apresentou-se a inclusão do conceito de humanização proposta pelo Ministério da Saúde aos ambientes de saúde, e o de acessibilidade por meio de uma análise da legislação vigente. A leitura da legislação é fundamental para desenvolver no aluno um referencial teórico e técnico, bem como a apropriação de conceitos e diretrizes legais.

O que vem coincidir com o proposto por Perrone e Vargas (2014) de que a abordagem do referencial teórico é fundamental para o desenvolvimento do projeto e para construir um 


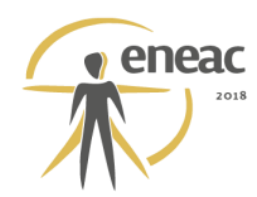

repertório para que o aluno responder aos desafios.

Através da literatura, os alunos começaram a observar que a elaboração de um projeto de arquitetura hospitalar passa por resoluções que são de caráter interdisciplinar entre arquiteto, engenheiro, médico, psicólogo.

A multidisciplinaridade e interdisciplinaridade demandará do aluno, enquanto arquiteto e urbanista, criar soluções físicas e que possam se adaptar à mudança mais maleável, renovável para se adaptar aos novos procedimentos de saúde e à evolução das tecnologias como robôs e videoconferência. Nesta perspectiva desenvolve-se no aluno a compreensão que embora as soluções são sejam muito acadêmicas ou simétricas, o fato é que o discente esteja preparado a construir conhecimentos que favoreçam as inter-relações entre as diversas áreas do saber.

Em resumo, no primeiro mês foram propostas as pesquisas bibliográfica e documental, com apresentações e debates; e, apresentação da legislação específica a Resolução de Diretoria Colegiada (RDC) no 50 para projetos físicos de estabelecimento assistencial de saúde e a Norma Brasileira (NBR) no 9050 sobre acessibilidade (ASSOCIAÇÃO BRASILEIRA DE NORMAS TÉCNICAS, 2004), finalizando com a visita a uma unidade hospitalar. Na visita apresentou-se aos alunos os ambientes de um hospital, como: centro cirúrgico, centro de material esterilizado, unidade de tratamento intensivo, área de carga e descarga dos insumos, acompanhada da observação quanto acessibilidade.

Para favorecer o efetivo entendimento acerca da acessibilidade, utilizou-se os layouts propostos pelo SomaSUS, do Ministério da Saúde para conhecer o mobiliário de cada ambiente e em seguida fazer um paralelo com a NBR 9050, que inclui o desenho universal, e verificar se esta é atendida.

O uso do desenho universal também foi adotado na concepção de espaços sem barreiras, artefatos e produtos construídos de forma atenda a todas as pessoas de forma autônoma, segura e confortável (BRASIL,2004).

Além disso, os sete princípios do desenho universal foram incorporados nas diretrizes projetuais que de acordo com Cambiaghi (2007) são os seguintes:

a) PRINCÍPIO 1 - Equiparação nas possibilidades de uso: O desenho universal não é elaborado para grupos específicos de pessoas, devendo, assim, atender a todos os grupos.

b) PRINCÍPIO 2 - Flexibilidade no uso: $O$ desenho universal atende a uma ampla gama de indivíduos, preferências e habilidades.

c) PRINCÍPIO 3 - Uso simples e intuitivo: $O$ desenho universal tem 0 objetivo de tornar o uso facilmente compreendido, independentemente da experiência do usuário, do seu nível de formação, conhecimento do idioma ou de sua capacidade de concentração.

d) PRINCÍPIO 4 - Informação perceptível: O desenho universal tem o objetivo de comunicar eficazmente aos usuários as informações necessárias, independentemente das condições ambientais ou da capacidade sensorial deste.

e) PRINCÍPIO 5 - Tolerância ao erro: O desenho universal tem o objetivo de minimizar o risco e as consequências de ações acidentais.

f) PRINCÍPIO 6 - Mínimo esforço físico: O desenho universal prevê a utilização, de forma eficiente e confortável, com o mínimo de esforço.

g) PRINCÍPIO 7 - Dimensionamento de espaço para acesso e uso de todos 


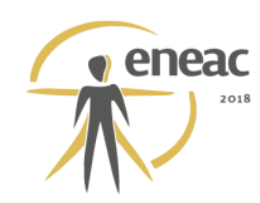

os usuários: O desenho universal tem o objetivo de oferecer espaços e dimensões apropriados ao uso, independentemente do tamanho ou da mobilidade do usuário.

No momento seguinte, os alunos passaram a analisar os determinantes antropológicos, topográficos, mercadológicos e legais para a implantação de um edifício e propor partido arquitetônico que equacione a situação - problema.

Para estimular os alunos a aprender, usou-se aqui o despertar da curiosidade proposta por Morin (2000) por meio da visita a um estabelecimento hospitalar para levantar o programa implementado, as dimensões dos ambientes, as complexas instalações, conforto acústico, sinalização, cores, ou seja, para entender as complexas relações espaciais inerentes ao edifício hospitalar, e ainda conceitos de contiguidade, flexibilidade, expansibilidade, humanização, e acessibilidade. A atividade extra sala de aula, portanto, possibilitou a percepção da realidade com a legislação e os critérios.

O relatório dessa visita foi apresentado em seminário constando das observações levantadas e de fotos, plantas e croquis. Nesse momento, todos identificaram as conformidades e as não conformidades com a legislação.

Diante disso, o exercício seguinte proposto foi a elaboração do programa de necessidades que é justificado pela RDC no 50 acompanhado da setorização dos ambientes, do entendimento do fluxograma e dos acessos e que atenda a diversidade humana de forma inclusiva.

Os ambientes são idealizados após a ampliação da percepção pelos estudantes de que as diferentes deficiências possuem campos de visão diferentes e que precisam se locomover sem riscos de acidentes, já que o cadeirante possui um campo de visão diferente da pessoa que se locomove a pé, e a pessoa que usa muletas está sempre olhando para baixo, por exemplo.

Os alunos passaram a compreender que para projetar ambientes acessíveis significa contribuir para a inclusão social ao criá-lo a partir da diversidade dos usuários.

Diante dessa coleta de dados, iniciou-se a etapa para desenvolver o partido arquitetônico adotado, em nível de projeto básico, atentando para os detalhes estruturais e de instalações prediais e viabilizando a inserção das edificações em proposta urbanística para a gleba.

O projeto de uma unidade hospitalar exigiu cuidado especial com o posicionamento de cada um dos seus ambientes, que possibilite iluminação e ventilação naturais, evite "proximidade de áreas que produzam ruídos, poeiras, fumaça e fortes odores” (GOÉS, 2004, p. 25).

Nesta etapa o aluno precisou identificar os problemas relativos à inserção destas unidades na estrutura urbana, devido a sua escala e complexidade e identificar os impactos físico funcionais, bem como a infraestrutura, a acessibilidade, uso do solo no entorno, a localização, topografia do terreno, clima, insolação, níveis de ruídos e legislação urbanística. Além disso, a largura dos passeios, acessos dos pacientes e funcionários, localização e o dimensionamento dos pátios de serviço e estacionamento tiveram que ser considerados.

O desenvolvimento da disciplina constou também da análise do entorno e tem como exercício propor o alcance ao equipamento de forma acessível e assim promover a inclusão social.

A etapa seguida se referiu a elaboração do projeto de urbanismo da área do terreno e com o seu entorno direto, o desempenho com relação às condições ambientais que interferem 


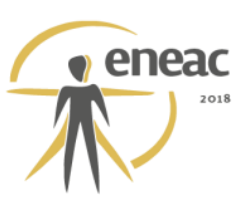

nesse controle, e com relação aos vários meios de transportes para esse local. Pro fim, demandou-se o desenvolvimento dos detalhes construtivos para a edificação, seu exterior e seu espaço interno, além do planejamento para a execução de obra.

A dinâmica adotada objetivou conquistar o aluno para se interessar ir além do produto esperado para a disciplina se proponha a elaboração um projeto piloto de uma sala nas dependências da instituição de ensino imbuída dos conceitos abordados no referencial teórico. Ou seja, de acessibilidade como promoção da inclusão social a partir de várias visões de forma humanizada.

\section{RESULTADOS E DISCUSSÃO}

No âmbito da disciplina de projeto arquitetônico hospitalar a acessibilidade vem sendo abordada mais como uma questão de execução de obra e encarada pelo aluno como mais um código a ser adotado para restringir sua criatividade ao impor regras.

A visão humanista se junta à acessibilidade como ferramentas fundamentais ao projeto arquitetônico para propor uma arquitetura inclusiva (DUARTE; COHEN, 2003).

O aluno entra em contato com a teoria e a legislação pertinente a partir do primeiro dia de aula na qual vem envolvida no conceito de acessibilidade como técnica para projetar o estabelecimento assistencial de saúde humanizado considerando a maior gama de diversidade humana.

Aos ensinamentos teóricos se juntam as experiências vivenciadas pelo aluno ao perceber e apreender o espaço a partir de diversos ângulos de visão, para o projeto contemplar a inclusão social.

A visita de campo segue um roteiro em que será observado além dos ambientes hospitalares o acesso a eles referente ao desenho universal.

Ainda não se aplicou nessa disciplina a vivência espacial ao simular situação por que passam as pessoas com deficiência como andar de cadeira de rodas, andar com vendas nos olhos, andar com muletas dentre outras. Essa metodologia tem como objetivo passar pelas sensações como frustração, vergonha, medo, insegurança, falta de autonomia são constantemente como chamam a atenção Duarte e Cohen (2003, p 10):

- a sensação de impotência ao não conseguir frequentar determinados espaços acadêmicos;

- a vergonha de pedir ajuda quando necessária;

- a sensação de um deficiente visual ficar perdido em espaços amplos e abertos;

- o cansaço gerado para percorrer superfícies mal pavimentadas;

- o constante medo de cair;

- a frustração por não conseguir visualizar objetos situados em estantes muito altas ou sobre balcões, como na disposição dos livros em bibliotecas,

- o medo por não conseguir ouvir alarmes de incêndio e a sensação de exclusão quando não se ouve o que estão falando ao seu redor;

- a revolta pela reação das pessoas que muitas vezes assumem atitudes de piedade, e a sensação de que estão sendo apontados por serem diferentes. 


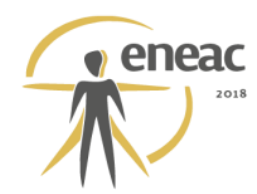

Essa simulação proporciona no aluno sem deficiência aspectos imperceptíveis a partir do ângulo de visão da pessoa com deficiência, e chama à atenção para considerar não somente a barreira física mas a monotonia visual.

Como trabalho futuro espera-se ampliar o trabalho a partir da transversalidade para proporcionar aos discentes de todas disciplinas do curso de Arquitetura e Urbanismo a oportunidade de uma formação que propicie ao aluno futuro arquiteto a percepção que o direito à cidade e à edificação é a promoção da qualidade de vida do cidadão.

Os resultados desta metodologia propõem-se a fazer o aluno a perceber que apesar de ser uma edificação hospitalar deve atender pessoas com deficiência ainda tem muito que fazer para torná-lo acessível em toda concepção.

\section{CONCLUSÃO}

Essa pesquisa trouxe à discussão da acessibilidade como meio de proporcionar a inclusão social, bem como mostrar que a inclusão social é pensar na igualdade de direitos e deveres de quem vive em sociedade.

A acessibilidade pela via do desenho universal traz inovação nas áreas de engenharia e arquitetura que se mostra indispensáveis à garantia dos direitos das pessoas com deficiência (CEARÁ, 2009).

$\mathrm{Na}$ medida em que as barreiras são identificadas constata-se que as necessidades das pessoas com deficiência, não foram incorporadas aos direitos de cidadania em nosso país. Os direitos civis fundamentais, como o de ir e vir, não existem para a realidade das pessoas com deficiência como observado nos relatos de Duarte e Cohen (2003).

Apesar de a Declaração Universal dos Direitos Humanos: "Todos os seres humanos nascem livres e iguais em dignidade e direitos. São dotados de razão e consciência e devem agir em relação uns aos outros com espírito de fraternidade" (ONU, 2009).

Tais direitos se aplicam a todos os indivíduos independentemente de sexo, raça, língua, religião ou deficiências, e estão acima de qualquer diferença e condição social. Incluem os direitos civis, políticos, econômicos, sociais, culturais e de desenvolvimento, sendo definidos em muitos documentos internacionais. São aspirações legítimas para todos os brasileiros, mas da dimensão do sonho para a pessoa com deficiência, só uma minoria os conquista. A partir de todas as situações expostas neste artigo, percebe-se que a cidade e seus espaços devem servir a todos.

Neste contexto, apresentou-se o termo acessibilidade como palavra que pode expressar possibilidades, alcance de objetivos, cumprimento de metas e justiça social. Além disso, oportuniza aos alunos a percepção que projetar não é uma atividade isolada, mas uma manifestação da compreensão da arquitetura e que esta se encontra inserida na cidade.

Desse modo, as leituras atualizadas possibilitam assinalar o processo de mudança na profissão. Essas leituras discutidas coletivamente viabilizam o processo de troca e, consequentemente, acontece a construção coletiva de novos conhecimentos docentes.

Percebe-se que as discussões e os exercícios propostos são recursos que contribuem para demonstrar que o projeto nasce da pesquisa possibilitando o desenvolvimento de novas propostas. $E$ também mostram que o ato de projetar não é uma situação isolada. 


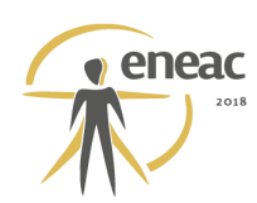

O ensino universitário está em constante mudança bem como a sociedade. É necessário que o professor reflita e pesquise sobre sua atuação para acompanhar as exigências necessárias a essas mudanças configurando um comprometimento maior com 0 desenvolvimento do aluno e da sociedade.

As novas práticas e perspectivas do ateliê de projeto podem favorecer o alcance dos programas pedagógicos, despertar a curiosidade do aluno e estimular sua participação no processo de aprendizagem. Provocar a sala de aula como um laboratório para superar as dificuldades e tornar a tarefa atraente e não somente deixar o aluno fazê-la para se livrar dela.

A proposta deste trabalho foi refletir sobre acessibilidade como inclusão social e que contribua na promoção de resultados favoráveis a partir da identificação e da associação dos valores nas atividades propostas pela disciplina, para proporcionar uma atuação diferenciada dos discentes em relação ao ato de desenvolver projetos arquitetônicos que são resultados dos questionamentos do porquê, para quem e como as coisas acontecem.

\section{REFERÊNCIAS BIBLIOGRÁFICAS}

ASSOCIAÇÃO BRASILEIRA DE NORMAS TÉCNICAS. ABNT. NBR: 9050. Acessibilidade a edificações, mobiliário, espaços e equipamentos urbanos. Rio de Janeiro, 2004.

BRASIL. Casa Civil. Decreto no 5.296, de 02 de dezembro de 2004. Regulamenta as Leis nos 10.048 , de 8 de novembro de 2000 , que dá prioridade de atendimento às pessoas que especifica, e 10.098, de 19 de dezembro de 2000, que estabelece normas gerais e critérios básicos para a promoção da acessibilidade das pessoas portadoras de deficiência ou com mobilidade reduzida, e dá outras providências.

Brasília. http://www.planalto.gov.br/ccivil_03/_ato2004-2006/2004/decreto/d5296.htm. Acesso em: jan. 2018.

Ministério da Educação. Conselho Nacional de Educação. Proposta de alteração da Resolução CNE/CES no 6/2006, que instituiu as Diretrizes Curriculares Nacionais do curso de graduação em Arquitetura e Urbanismo, em decorrência de expediente encaminhado pela SESu/MEC., de 02 de setembro de 2009. PARECER CNE/CES №: 255/2009. Relator: Edson de Oliveira Nunes.

Convenção sobre os Direitos das Pessoas com Deficiência; Protocolo Facultativo à Convenção sobre os Direitos das Pessoas com Deficiência; decreto legislativo no 186, de 09 de julho de 2008; decreto no 6.949, de 25 de agosto de 2009. 4.ed., ver. e atual. - Brasília: Secretaria de Direitos Humanos, Secretaria Nacional de Promoção dos Direitos de Pessoas com Deficiência, 2001.

CAMBIAGHI, Silvana. Desenho universal: Métodos e Técnicas para Arquitetos e Urbanistas/ Silvana Cambiaghi. São Paulo: Editora Senac São Paulo, 2007.

CEARÁ, Governo do Estado. Guia de Acessibilidade: espaço público e edificações. Secretaria da Infraestrutura (SEINFRA). Fortaleza, 2009.

DUARTE, Cristiane Rose de Siqueira ; COHEN, R. O Ensino da Arquitetura Inclusiva como Ferramenta para Melhoria da Qualidade de Vida para Todos. In: PROJETAR 2003. (Org.). Projetar: Desafios e Conquistas da Pesquisa e do Ensino de Projeto. Rio de Janeiro: Virtual Científica, 2003, p. 159-173.

GÓES, Ronald de. Manual prático de arquitetura hospitalar. São Paulo: Edgard Blücher. 2004. 


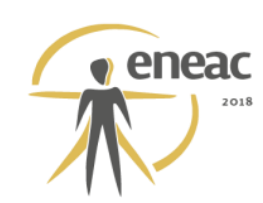

MORIN, Edgar. Os setes saberes necessários à educação do futuro. São Paulo: Cortez. 2000.

Disponível em: <http://www.proletariosmarxistas.com/docs/.../os\%20sete\%20saberes.pdf >.Acesso em: 13 mai. 2015.

MORUZZI, Andréa Braga; MORUZZI, Rodrigo. A transversalidade como princípio pedagógico no ensino superior de engenharia: o ProGAmAR da engenharia ambiental da Unesp - Campus de Rio Claro. In: Revista de Ensino de Engenharia, v. 29, n. 1, p. 20-28, 2010.

ONU. Organização Mundial das Nações Unidas. Declaração Universal dos Direitos Humanos. UNIC. Janeiro, 2009. Disponível em: <http://www.onu.org.br/img/2014/09/DUDH.pdf>. Acessado em: 10 jan. 2015.

PERRONE, R. A.; VARGAS, Heliana Comin. Fundamentos de Projeto: Arquitetura e Urbanismo. São Paulo: Editora da Universidade de São Paulo, 2014.

SANTOS, Akiko. O que é transdisciplinaridade. 2005 Disponível em: <http://www.ufrrj.br/leptrans/arquivos/O_QUE_e_TRANSDISCIPLINARIDADE.pdf>. Acessado em: 16 ago. 2015.

SILVEIRA, Aline Montagna da; REGO, Renato Leão; MENEGUETTI, Karin Schwabe; BOTELO, Gislaine Elizete. Reflexões sobre o processo de ensino-aprendizagem. O caso da oficina sistemas de espaços livres, em Maringá. Revista Tecnológica, Edição Especial ENTECA 2009, p. 117-125, 2009. 